REVISTA X, Curitiba, volume 12, n.3, p.28-46, 2017.

\title{
LETRAMENTO DIGITAL: PRÁTICAS INTERDISCIPLINARES ATRAVÉS DA TELA DO COMPUTADOR
}

\section{Digital Literacy: interdisciplinary practices through the computer screen}

\author{
Jean Michel VALANDRO - UNIVATES ${ }^{1}$ \\ Monique IZOTON - UNIVATES ${ }^{2}$ \\ Mariane MALLMANN - UNIVATES ${ }^{3}$ \\ Maristela JUCHUM - UNIVATES ${ }^{4}$
}

\begin{abstract}
RESUMO: O presente trabalho visa apresentar práticas docentes mediadas pelo uso das Tecnologias Digitais de Informação e Comunicação (TDICs), com o intuito de promover tarefas interdisciplinares desenvolvidas pelos estudantes que integram $o$ Programa Institucional de Bolsas de Iniciação à Docência - PIBID/Univates em uma escola situada na cidade de Lajeado/RS. Tendo por objetivo superar a compartimentalização do conhecimento no ambiente escolar, o trabalho dos bolsistas buscou unir diferentes disciplinas em torno de um tema comum. A prática pedagógica compreendeu o planejamento de tarefas pautadas pelos gêneros discursivos e pelo uso de tecnologias digitais. Como resultados, pode-se dizer que, para além de muitos fatores, os principais foram a mudança de visão quanto ao ensino na escola, uma vez que os alunos passaram a enxergar as disciplinas de maneira menos separada, o que indicou um avanço em direção à interdisciplinaridade no ambiente escolar e também a construção do entendimento da reescrita textual como um processo de aprendizagem e não só como uma maneira negativa de ver o erro.
\end{abstract}

PALAVRAS-CHAVE: Educação; Interdisciplinaridade; Tecnologias Digitais de Informação e Comunicação; PIBID.

ABSTRACT: This paper aims to present teaching practices mediated by the use of Information and Communication Digital Technologies (ICDTs) in order to promote interdisciplinary activities developed by the scholars from the Programa Institucional de Bolsas de Iniciação à Docência - PIBID/UNIVATES in a school of Lajeado/RS. Intending to overcome the knowledge compartmentalization in the school environment the scholars' work sought to unite different disciplines around a common theme. The methodology consisted in the planning of an instructional sequence guided by the use of discursive genres and digital technologies. As results, we may say that beyond many factors the main ones are the change in the point of view about the teaching at school since the students start to observe the disciplines in way in that they are not apart, which pointed out a progress toward interdisciplinary in the school environment. In addition,

\footnotetext{
${ }^{1}$ Graduado em Letras - português/inglês

${ }^{2}$ Graduada em Letras - português/espanhol

${ }^{3}$ Professora Supervisora do subprojeto Interdisciplinar do Ensino Fundamental do PIBID/Univates

${ }^{4}$ Dra. Coordenadora de Área do subprojeto Interdisciplinar do Ensino Fundamental do PIBID/Univates
} 
we noticed the construction of the concept that the rewriting is also a process of learning and not only a negative way of seeing the errors.

KEY WORDS: Education; Interdisciplinary; Information and Communication Technologies; PIBID.

\section{INTRODUÇÃO}

“[...] a minha questão não é acabar com a escola, é mudá-la completamente, é radicalmente fazer que nasça dela um novo ser tão atual quanto a tecnologia. Eu continuo lutando no sentido de pôr a escola à altura do seu tempo. E pôr a escola à altura do seu tempo não é soterrá-la, mas refazê-la” (FREIRE \& PAPERT, 1996)

O subprojeto Interdisciplinar do Ensino Fundamental (IEF) do Programa Institucional de Bolsas de Iniciação à Docência - PIBID - é relativamente novo na Univates, uma vez que teve seu início no ano de 2014. Porém, o caminho trilhado pelos bolsistas do programa já demonstra avanços quanto à superação da fragmentação dos conteúdos escolares à medida que se pode perceber que a prática pedagógica desenvolvida atende ao conceito de interdisciplinaridade.

A Universidade do Vale do Taquari - Univates é uma instituição privada de ensino superior que existe desde meados de 1969 na cidade de Lajeado/RS. Ela abriga o PIBID, programa do MEC que visa ao incentivo do magistério, desde o ano de 2010. Em 2014, quando foi realizada a prática descrita neste artigo, o programa contava com 10 subprojetos - todas as licenciaturas da instituição -, dos quais faziam parte aproximadamente 100 bolsistas, 10 coordenadores de área e um número oscilante de professores supervisores que provinham da escola pública. As reuniões dos subprojetos eram feitas duas vezes na semana, sendo uma delas na universidade com o objetivo de capacitação e planejamento e a outra na escola no intuito de ministrar as atividades planejadas previamente.

É pertinente que se deixe claro que a concepção dos bolsistas do IEF é a de que os projetos de trabalho possibilitem uma abordagem interdisciplinar, isto é, escolhe-se um tema como fio condutor do planejamento das aulas. Além disso, acredita-se que também seja imprescindível que as práticas desenvolvidas com os aprendizes partam de 
REVISTA X, Curitiba, volume 12, n.3, p.28-46, 2017.

perguntas norteadoras que devem surgir a partir das dúvidas dos estudantes em relação ao tema proposto.

Partindo dessa perspectiva, foram desenvolvidas práticas pedagógicas, que serão comentadas mais adiante, na Escola Municipal de Ensino Fundamental Porto Novo, localizada no município de Lajeado/RS. Inicialmente, pensou-se em trabalhar com várias turmas, dividindo o número de bolsistas para cada uma delas, sendo que estávamos em cinco e desejávamos atuar em duas turmas por vez. Entretanto, as professoras da escola sugeriram que ficássemos juntos e desenvolvêssemos as práticas somente com as duas turmas de oitavo ano com, aproximadamente, 40 alunos no total.

A escola havia definido, como tema para os estudos de 2014 a frase: Navegar é preciso, mas conviver é imprescindível e foi a partir dela que organizamos nossas práticas utilizando como base as Tecnologias Digitais da Informação e Comunicação TDICs. O projeto criado objetivou, para além da interação com as TDICs, que contemplava a parte do "navegar", a conscientização de como utilizar os ambientes virtuais de interação de forma idônea, moderada e responsável, o que deu conta da parte do "conviver". Ainda, o propósito principal foi mostrar aos aprendizes a potencialidade das tecnologias digitais como ferramenta de aprendizado e como elas podem vir a enriquecer o atual contexto de ensino consolidado na escola.

O projeto supracitado foi desenvolvido com base em uma sequência didática que compreendeu diversas tarefas ao longo do segundo semestre de 2014. Neste artigo, explicaremos como foram ministradas as tarefas propostas, como a interdisciplinaridade aconteceu e quais disciplinas participaram da resolução das questões levantadas, além de comentar acerca dos resultados alcançados.

\section{REFERENCIAL TEÓRICO}

Nesta seção estão descritos os aportes teóricos que nortearam não só o planejamento das ações desenvolvidas na escola, mas também os estudos acerca de interdisciplinaridade e uso de tecnologias digitais no âmbito escolar.

\subsection{O que se entende por interdisciplinaridade}

Muito já se tem dito sobre diversos conceitos de ensino atualmente em voga no contexto escolar, dentre eles pode-se destacar a multi, a trans e a interdisciplinaridade que, apesar de diferentes, são separadas por uma linha bastante tênue. Portanto, quando 
se fala sobre interdisciplinaridade deve-se ter o cuidado de refletir sobre a prática pedagógica realizada no sentido de que nem tudo o que se diz interdisciplinar de fato o é.

Para esclarecer e definir o que significam os três termos acima, leva-se em conta o que diz Pires (1998) quando afirma que, na multidisciplinaridade, as disciplinas do currículo de uma determinada escola e os profissionais que nela atuam desenvolvem seu trabalho de maneira próxima, mas nunca conjunta, ou seja, cada qual atua em sua área de formação sem promover interação nenhuma entre as áreas do conhecimento. Já a interdisciplinaridade, ainda segundo a mesma autora, possibilita a desfragmentação das disciplinas escolares mediante a colaboração de duas ou mais disciplinas para a construção do conhecimento. Isto é, a interdisciplinaridade ainda não abandona a questão do estabelecimento de disciplinas no ambiente escolar, mas faz com que elas interajam entre si no intuito de resolver um dado problema por meio de discussão e construção conjunta de soluções.

Dos três termos, o mais difícil de conceituar e, talvez, de colocar em prática no atual cenário da educação brasileira seja a transdisciplinaridade. Pires (1998) ressalta que essa dinâmica de trabalho busca inspiração nas teorias do holismo e da complexidade e ela possui elementos que perpassariam por entre e para além da disciplinaridade já estabelecida na escola, quebrando com a ideia de compartimentação do saber. Nesse ponto de vista, então, a transdisciplinaridade seria uma interdisciplinaridade aprimorada, porque para além do diálogo formador de conhecimento, ela pretende que se abandone a noção de disciplina tão fortemente arraigada em nossas instituições de ensino.

Retornando então ao foco deste artigo, Carlos (2001) afirma que falar sobre o fazer pedagógico com foco interdisciplinar é estabelecer uma relação de interação entre as disciplinas do currículo escolar com o intuito de fazê-las cooperar entre si. Essa cooperação deve estar embasada pelo diálogo que se manifesta na construção do conhecimento de maneira coordenada, ou seja, as disciplinas agem juntas para a resolução de um determinado problema.

Também, como um dos pilares fundadores de nossos conceitos sobre interdisciplinaridade está o que diz Thiesen (2008, p. 547) quando afirma que a “interdisciplinaridade está sempre situada no campo onde se pensa a possibilidade de 
superar a fragmentação das ciências e dos conhecimentos produzidos por elas e onde simultaneamente se exprime a resistência sobre um saber parcelado". Isto é, interdisciplinaridade é, em sua essência, uma prática educativa que quebra com o paradigma de ensino disciplinar da escola que separa e de certa forma encerra as disciplinas dentro de limites bastante rígidos, não permitindo que elas interajam entre si na construção do conhecimento.

Nesse sentido, acredita-se que um dos principais elementos do trabalho interdisciplinar sejam os trabalhos de pesquisa. Assim como no Ensino Médio, o Ensino Fundamental deve instigar os alunos a produzirem conhecimento científico porque, à medida que investigam, descobrem um novo método de construção e ampliação de conhecimento que complementa aquele iniciado antes mesmo da educação formal. Além disso, o trabalho de pesquisa ajuda a contribuir com a construção de um estudante que seja sujeito de sua aprendizagem, ou seja, que atue ativamente na construção do saber. Os trabalhos de pesquisa, ainda, permitem encontrar respostas às demandas surgidas dentro do contexto escolar frente a uma determinada necessidade expressada pelos alunos, professores ou pela escola. Afirma-se isso com base no fato de que

[...] é importante enfatizar que a interdisciplinaridade supõe um eixo integrador, que pode ser o objeto de conhecimento, um projeto de investigação, um plano de intervenção. Nesse sentido ela deve partir da necessidade sentida pelas escolas, professores e alunos de explicar, compreender, intervir, mudar, prever, algo que desafia uma disciplina isolada e atrai a atenção de mais de um olhar, talvez vários. Explicação, compreensão, intervenção são processos que requerem um conhecimento que vai além da descrição da realidade, mobiliza competências cognitivas para deduzir, tirar inferências ou fazer previsões a partir do fato observado (BRASIL, 2002, p. 88-89).

Levando em consideração o dito até o momento, Zabala (2002) afirma que o fato de que a interdisciplinaridade, para além de algo que somente explica as relações entre as disciplinas, é uma forma de trabalho que facilita a construção do saber porque constitui-se como um conteúdo que auxilia no encadeamento de ideias de diversas áreas do saber. Além disso, o trabalho interdisciplinar auxilia na compreensão do mundo que nos rodeia, de seus problemas e facilita, nas palavras do autor "a elaboração de um conhecimento mais holístico e complexo" (ZABALA, 2002, p. 80).

Nessa perspectiva, ainda de acordo com Zabala (2002), a interdisciplinaridade seria um conteúdo prioritário do ensino. Estabelecer conexões entre as diferentes áreas 
do conhecimento, independentemente de sua natureza, seria a melhor resposta ao conhecimento fragmentado de uma instituição - escola - que, no decurso da história, distanciou-se das necessidades cidadãs dos educandos.

\subsection{A interdisciplinaridade e sua relação com a escola contemporânea}

Conforme Silva e Pinto (2009), as habilidades e competências para o bom desenvolvimento das práticas escolares que visam à ciência e ao mundo do trabalho não podem mais ser vistas como as que permeiam o modelo de escola que privilegia o conteudismo e que serviu bem a uma época cujos propósitos atendeu devidamente. Esse modelo que privilegia a disciplinaridade, ou seja, a construção do conhecimento dividido em áreas específicas é o que se percebe nas escolas contemporâneas. Essa compartimentalização do conhecimento faz com que o aluno, na maioria das vezes, não consiga conectar suas aprendizagens, formando um saber unificado.

Se prestarmos atenção, veremos que os estudos realizados antes do modelo conteudista de escola citado acima já possuíam evidências de ser interdisciplinar, ainda que o termo não estivesse cunhado nos anais da educação. Como afirma Leis (2005, p. 3), "nos mundos clássico e medieval, os pesquisadores não estavam muito preocupados em estabelecer limites significativos entre os vários conhecimentos disponíveis à época".

Para entender o porquê de a escola ainda trabalhar da maneira como trabalha, é necessário observarmos a forma como se compreendia a ciência há pelo menos dois séculos. Segundo Silva e Pinto (2009), o fazer científico via como fundamental a divisão do objeto de estudo em diversas partes para melhor poder compreender cada uma delas, o que, no caso da escola, deu origem à fragmentação do conhecimento, às diversas disciplinas. Esse processo acaba por deixar de lado a relação entre todas as partes desse quebra-cabeça e a própria reconstrução dessas partes em um todo.

Dessa forma, o conteudismo consolidou-se, conforme o que afirma Paviani (2008), com o surgimento das primeiras universidades e das carreiras que exigiram a criação de um sistema organizacional e administrativo de cursos oferecidos. Ou seja, à medida que o número de universidades aumentava, também aumentava a popularidade do modelo de ensino que, para além de critérios epistemológicos envolvia questões políticas. A instauração, portanto, desse modelo disciplinar de ensino, de acordo com 
Leis (2005) e Morin (2008), foi vantajoso do ponto de vista da divisão do trabalho, porém causou superespecialização e entrincheiramento dos pesquisadores que acabaram por confinar o saber. As discussões científicas passaram a ser feitas somente dentro de grupos restritos.

Partindo, então, da ideia de que o modelo atual de escola produz ciência de forma fragmentada, Alves et al. (2004) diz que se deve superar os polos extremistas nos quais tentamos enquadrar a ciência e concorda com Demo (1998) quando afirma que tanto a disciplinaridade quanto a interdisciplinaridade são importantes no processo de construção científica. Demo assinala que a ciência só evoluiu a tal ponto devido à especialização proporcionada pela divisão do objeto de estudo, mas ele também acredita ser imprescindível que os especialistas de diferentes áreas do conhecimento sejam capazes de estabelecer diálogo com todos os demais.

Nesse sentido, a interdisciplinaridade citada nesta seção e na anterior acontece através do diálogo entre as áreas do saber porque, uma vez que elas conversam entre si, deixam de lado seu estado fragmentado para construir uma área comum de interação em que todas elas colaboram para a solução de uma determinada situação-problema. Essa situação-problema pode já existir previamente ou ser fictícia, criada exclusivamente para fins educativos em sala de aula, como o caso do projeto apresentado neste artigo, que se restringiu a pesquisar assuntos que eram de interesse dos alunos, isto é, foram situações-problema, ou perguntas de pesquisa criadas por eles.

\subsection{0 contexto social do desenvolvimento tecnológico}

Sabe-se que as transformações são uma constante na vida, mas, segundo Forquin (2003), na sociedade atual elas têm assumido um caráter geral e de natureza inesperada, dado que o ritmo em que as mudanças vêm acontecendo afetou a relação entre as gerações, principalmente no que diz respeito a modelos comportamentais. Os modelos de vida do passado já não condizem com aqueles em que as atuais gerações acreditam, pois, os mais jovens constituem-se como uma geração com maior acesso à informação, mais competentes e adaptados à sociedade atual. Ainda de acordo com o autor, as crianças nascidas no decorrer dos últimos vinte anos sabem mais do nosso mundo do que um adulto que cresceu dentro de um sistema cultural relativamente mais fechado.

No ambiente escolar atual, pode-se observar três gerações em "conflito" que, conforme o panorama supracitado, são a geração $\mathrm{X}$, a geração $\mathrm{Y}$ e a geração $\mathrm{Z}$. $\mathrm{O}$ 
conflito propriamente dito pode ser caracterizado por divergências ideológicas de uma geração com relação às outras, visto que a geração $\mathrm{Y}$ e $\mathrm{Z}$ são bastante parecidas, havendo apenas algumas pequenas diferenças entre as duas que serão explicadas a seguir.

A geração X, segundo o que delimita Oliveira (2009) é a que engloba os nascidos entre 1960 e 1980. Essa geração teve seus hábitos influenciados pelos programas de televisão que os moldou tanto com relação à rotina familiar quanto com relação à escolar. Isso fez com que os indivíduos dessa geração fossem mais consumistas e reprogramassem seu modo de vida para que ele estivesse à altura daquilo em que acreditavam.

Já entre a geração Y e Z há uma tênue linha que as difere e, por vezes, as datas de separação entre as duas não são muito precisas. Contudo, a maioria dos autores concorda que a geração Y é aquela dos indivíduos nascidos entre 1980 e meados da década de 1990 e refere-se, conforme diz Lombardia (2008), à camada populacional que, em oposição à geração $\mathrm{X}$, está adentrando o mercado e faz parte de um período econômico de prosperidade. Essa é a geração dos resultados a curto prazo, excesso de segurança e que é constantemente estimulada.

Delimitando a geração Y, pode-se então falar na geração Z, que seriam aquelas pessoas nascidas em meados dos anos 90 até a atualidade. O "Z", como explica Toledo et al. (2012) vem da palavra "zapear", que significa trocar rapidamente e com certa constância os canais da televisão na busca de algo que prenda a atenção e, ainda segundo os autores, a palavra "zap", oriunda do inglês tem como significado "fazer algo muito rapidamente" e também "energia" ou "entusiasmo". Para os autores, a geração Z é formada de integrantes continuamente conectados por dispositivos portáteis e bastante preocupados com assuntos ambientais. Toledo et al. (2012) também salienta que a geração $\mathrm{Z}$ pode ser integrante ou meramente uma parte da geração $\mathrm{Y}$, uma vez que suas características são quase as mesmas e os períodos de término de uma e surgimento da outra confundem-se em alguns pontos.

Tendo em vista o já escrito, pode-se perceber que, dentro do ambiente escolar, é possível encontrar, se não todas, pelo menos duas das gerações acima citadas, sendo que uma delas está no papel de educador e a outra, no de educando. Um dos fatores que 
dificultam a interação entre as gerações coexistentes é a diferença no modo de se comunicarem que encontra justificativa no fato de que

a rápida expansão do uso do computador na sociedade, especialmente depois do advento da Internet, vem produzindo um profundo impacto em todas as áreas da atividade humana - educação, ciência, entretenimento, negócios, etc. Nesta era na qual a sociedade encontra-se conectada mundialmente, transformou-se radicalmente a maneira de se comunicar, de adquirir informação e produzir conhecimento (NASCIMENTO, 2010, p. 2).

Para complementar a ideia acima citada, Casarin (2013) afirma que, como qualquer outro setor social, a escola não pode ficar à margem de toda essa mudança na forma de comunicar-se e/ou de adquirir informações para a produção de conhecimento científico. Entende-se isso com base no fato de que a escola é uma instituição de formação sociocultural e deve acompanhar a sociedade em suas mudanças para poder formar indivíduos que não sejam alienados, mas que possam olhar criticamente as transformações que ocorrem em seu entorno.

\subsection{A diferença entre TICs e TDICs e sua utilização nas práticas educacionais}

É comum que, ao falar sobre as Tecnologias de Informação e Comunicação (TICs), os desavisados confundam-nas com TDICs. Essas segundas não possuem um propósito tão diferente das primeiras, mas há alguns detalhes que devem ser observados. Conforme os dados levantados por Brasil (1998, p. 135), os Parâmetros Curriculares Nacionais (PCNs) definem as TICs como "recursos tecnológicos que permitem o trânsito de informações, que podem ser os diferentes meios de comunicação (jornalismo impresso, rádio e televisão), os livros, os computadores, etc.".

Já as TDICs, segundo Afonso (2002), são aquelas tecnologias que, assim como as anteriores, têm por propósito facilitar o veículo de informações, porém diferenciamse pela presença do digital. São exemplos dessa categoria os computadores, os notebooks, os tablets, os smartphones, as lousas digitais, os Datashow. Sendo assim, todas as TDICs estão inseridas dentro do grupo maior que são as TICs.

Além disso, desde o seu surgimento as tecnologias digitais têm sido cogitadas como instrumentos a serem utilizados no contexto escolar por seu caráter facilitador de acesso a redes de informação. Sabe-se que a rede privada tem utilizado aparelhos digitais mais seguidamente do que a rede pública, até mesmo por suas condições de aquisição de dispositivos. Entretanto, a rede pública vale-se de programas 
governamentais que, segundo Araujo e Carvalho (2014), tentam inserir a tecnologia na escola através do ProInfo4 e de projetos como "Um computador por aluno", "Acessa Escola", entre outros.

Lembrando o dito anteriormente, é papel fundamentalmente de a escola acompanhar as mudanças da sociedade que, conforme cita Duarte (2003), acontecem de maneira muito rápida atualmente. $\mathrm{O}$ autor diz que a educação tradicional, estática, na qual o conhecimento construído anteriormente bastava para formar as gerações seguintes, não supre mais todas as necessidades do atual panorama educativo e afirma que a necessidade de se atualizar nessa nova sociedade mais dinâmica do que as anteriores para que não nos tornemos seres com conhecimentos defasados. Entretanto, é necessário, do ponto de vista de Kenski (2001), entender as potencialidades de cada tecnologia e valorizá-las de maneira a fazer com que seu uso possa ser fator de transformação pedagógica. Isto é, deve-se estar atento às necessidades educativas de cada público para que a tecnologia escolhida seja eficaz tanto no processo de ensino quanto no de aprendizagem. Além disso, para que essa eficácia não seja prejudicada, o professor também deve exercer um papel diferenciado do que ainda exerce em muitas instituições de ensino, perspectiva que será explorada no item a seguir.

\subsection{O papel do professor e do aprendiz na educação mediada pelas TDICs}

A perspectiva interdisciplinar de trabalho também é facilitada pelo uso das tecnologias, porque na Internet as informações não estão separadas por área, não pertencem somente a uma disciplina específica como a divisão dos estudos escolares. Sendo assim, o aluno compreenderá, através da mediação do professor, a importância do diálogo entre as diversas áreas do conhecimento a fim de construir um produto final. Para tanto, é necessário também instrumentalizar os professores quanto ao uso de diversas tecnologias, já que a maioria dos professores do atual mercado de trabalho pertence à geração $\mathrm{X}$, que não tem muita afinidade com as tecnologias digitais. Esse processo de ensinar a ensinar pela tecnologia é interessante, pois, conforme Grané (2011, p. 67, tradução nossa), “em muitos casos as tecnologias na escola tiveram um 
papel curricularizador de reprodução de modelos tradicionais de ensino, quando na realidade, poderiam ter sido um elemento revolucionário"5.

Do ponto de vista da educação mediada pelas tecnologias digitais, tem-se uma mudança de olhar quanto aos papéis desempenhados pelo professor e pelo aluno. Portanto, faz-se fundamental um trabalho de adequação aos novos padrões de trabalho, caso contrário a tecnologia perde o seu valor como importante meio de busca de informação. Essa ideia encontra seu embasamento em Pozo e Echeverría (2001) que afirmam ser necessária uma mudança de mentalidade para que o trabalho com as TDICs seja, de fato, significativo, porque sem isso, as concepções arraigadas sobre aprendizagem não deixarão que se encare de maneira apropriada essa nova cultura do aprender.

Afirma-se isso porque o professor deixaria de ser a única fonte de informação da sala de aula, passando a ser o mediador entre a informação e o aluno e porque sobre o aluno recairia mais responsabilidade por seu ensino, uma vez que ele ficaria encarregado de buscar a informação em sua fonte e analisar sua pertinência, sua veracidade, entre outros. Nessa perspectiva, Lévy (1999) diz que o professor deve acompanhar a aprendizagem e incentivar a troca de saberes com o intuito de tornar o aluno sujeito de sua aprendizagem.

Partindo desses pressupostos, é necessário que sejam admitidas, segundo Coscarelli (2009), as diversas falhas que temos nos cursos de formação de professores que se pautam nos modelos tradicionais de ensino. Observa-se que, na atualidade, os professores têm tido uma maior aceitação do uso de computadores em suas práticas pedagógicas, porém ainda é grande o número de docentes que mostra severa aversão às tecnologias digitais que poderiam, segundo o autor supracitado, promover a aprendizagem colaborativa sem a necessidade de aulas expositivas.

\section{PRÁTICAS PEDAGÓGICAS ENVOLVENDO AS TDICS}

Com o intuito de contribuir para a formação de crianças e adolescentes conscientes da importância da convivência social, além de desenvolver um trabalho que

\footnotetext{
${ }^{5}$ En muchos casos, las tecnologías en la escuela tuvieron un papel curricularizador de reproducción de modelos tradicionales de la enseñanza, cuando, en realidad, podrían haber sido un elemento revolucionario.
} 
abordasse aspectos relacionados às TDICs, a escola parceira do PIBID desenvolveu o projeto Navegar é preciso, mas conviver é imprescindível. As tarefas do projeto versaram sobre o letramento digital embasado por gêneros textuais produzidos em ambientes virtuais, tais como: e-mail, postagem em rede social (Facebook) e crônicas em suportes digitais como blogs e jornais on-line.

Dentro do projeto citado acima, a atuação dos bolsistas do PIBID aconteceu entre os meses de agosto e dezembro do ano de 2014, totalizando aproximadamente 20 aulas -80 horas. Além disso, o grupo era formado, como dito anteriormente, por 5 bolsistas de iniciação à docência, uma professora coordenadora de área, uma professora supervisora que provinha da escola parceira onde ministrava aulas de Língua Portuguesa, além de 40 alunos. A seguir, estão descritas as tarefas realizadas por ordem cronológica.

\subsection{Metodologia de trabalho}

Nesta seção abordaremos a metodologia de trabalho, ou seja, como foram desenvolvidas as atividades com os alunos acima mencionados. Entretanto, antes de mais nada, é interessante que se diga que a escolha das turmas com as quais promoveram-se as atividades a serem descritas deu-se por meio de conversa com a equipe diretiva da escola e corpo docente, bem como com os bolsistas do PIBID que, na ocasião, socializaram com o grupo os planejamentos elaborados para o semestre por meio de apresentação de slides.

As metodologias escolhidas para o trabalho foram pinçadas do rol de metodologias ativas, que são aquelas em que o aluno ganha protagonismo na construção do conhecimento, pois torna-se sujeito de seu aprendizado e produtor de saber em conjunto com o professor mediador de uma dada tarefa. Exemplos dessas metodologias são o ensino através de canções, de vídeos, de pesquisas, a sala de aula invertida, entre outros.

Para tanto, a primeira tarefa foi assistir a dois vídeos intitulados Como surgiu e como funciona o computador e Surgimento e evolução da Internet. Esses vídeos foram assistidos no laboratório de informática em duas etapas, uma com cada turma de 20 alunos, e a proposta era que eles assistissem aos vídeos sem explicação nenhuma para que houvesse a desacomodação inicial e, em seguida, eles questionassem o porquê dos 
vídeos. No decorrer do diálogo de apresentação da proposta de trabalho já foram levantadas algumas questões-problema, o que aconteceu naturalmente.

Após esse levantamento de questões, os aprendizes foram desafiados a pesquisar eles mesmos respostas para seus questionamentos, porém, para que a busca se tornasse um pouco diferente das demais já realizadas pelos professores da escola, os temas foram sorteados e, dessa maneira, eles responderiam aos questionamentos dos colegas e nãos os deles próprios. A pesquisa também aconteceu no laboratório de informática da mesma maneira que na execução do vídeo, com uma turma por vez, e nesse processo de pesquisa frisou-se tempo todo a necessidade de encontrar fontes de informação que fossem confiáveis e como seria a melhor maneira de apresentar os resultados encontrados aos colegas utilizando algum gênero textual escrito ou oral, se por meio de infográficos, apresentação de slides, com vídeos, através de experiências práticas, relatos falados, depoimentos etc.

Depois das pesquisas e da abordagem inicial de gêneros textuais supracitados, os alunos deveriam escrever também um e-mail para compartilhar as descobertas feitas através da pesquisa de maneira resumida, visto que o gênero textual em questão não é dado a mensagens longas e sim a escritas concisas, objetivas e diretas. Essa atividade de escrita também serviu para que nós tivéssemos consciência dos conhecimentos prévios dos alunos com relação à Língua Portuguesa, uma vez que foi solicitado que eles escrevessem dois textos com diferentes interlocutores: um direcionado a um amigo ou familiar contando de suas descobertas recentes e o outro direcionado a um editor de uma revista (fictícia) em que eles gostariam de publicar sua pesquisa. Para que os bolsistas conseguissem avaliar os textos escritos pelos alunos os endereços de e-mail para os quais eles foram enviados eram os dos próprios bolsistas.

A atividade seguinte foi de releitura e reescrita coletiva dos textos dos alunos, já que o que se pretendia é que ficasse claro quais estruturas linguísticas podem ser utilizadas em registros mais formais de escrita e em registros mais coloquiais. Além disso, com a permissão dos alunos, alguns textos foram discutidos e reescritos coletivamente para que todos percebessem algumas marcas de oralidade que estavam presentes nos textos mais formais, além de inadequações sintáticas e ortográficas. Ainda nessa aula foi introduzido o tema "netiqueta" - etiqueta na internet - que, segundo a proposta do projeto, visava auxiliar os alunos a entenderem algumas regras de bom 
comportamento em ambientes virtuais e como expressar-se de maneira escrita a fim de que seu texto não provocasse mal-entendidos.

Seguindo o trabalho com gêneros textuais em ambientes digitais, foram elaboradas três aulas relativas à produção de crônicas, gênero de larga circulação em formato on-line. Foi apresentada aos alunos a estrutura "padrão" de uma crônica por meio de apresentação de slides e um material escrito entregue a cada um. A partir disso, os alunos também puderam observar a estrutura da crônica e compará-la aos quesitos elencados no material recebido durante a leitura do texto de David Coimbra, Minha cidade-sorriso, promovida em sala de aula. Logo após, deu-se tempo para a produção de textos, primeiramente, no editor de textos do Office (Microsoft Word) e, em seguida, foi feita sua transposição para suporte on-line, sendo que elas foram postadas no blog da escola gradualmente durante o semestre.

Concomitante à produção das crônicas, aconteceu a criação de um grupo de Facebook para produção de outro gênero textual, a postagem em rede social. Essas postagens tiveram por motivação datas festivas e atividades internas da escola que deveriam ser informadas aos participantes do grupo. Partindo da ideia abordada na crônica de Coimbra acima mencionada e do grupo de Facebook, pensou-se em uma atividade que servisse de produção de um produto final, portanto, a última tarefa contemplou a produção de um vídeo cujo tema foi "o que faz você feliz?". Como maneira de instrumentalizar a produção do vídeo, os alunos participaram de uma oficina de edição de vídeos e, em seguida, produziram seu material individualmente. As produções deveriam ser postadas no grupo criado no Facebook com o intuito de divulgar todo o trabalho dos alunos.

\subsection{A conexão entre as áreas do conhecimento: construindo relações interdisciplinares}

Segundo conceitos previamente definidos neste artigo, sabe-se que a interdisciplinaridade é caracterizada como uma prática pedagógica cuja dinâmica de trabalho permanece atrelada à noção de disciplinaridade, porém faz com que duas ou mais áreas do conhecimento mobilizem-se na construção de um determinado conhecimento. Isto é, faz com que haja diálogo entre disciplinas do currículo que antes 
atuavam isoladamente na intenção de tornar mais profícuo o processo de ensino e de aprendizagem.

Tendo em vista esse conceito cunhado anteriormente e as práticas pedagógicas apresentadas no item 3.1, pretende-se agora explanar como aconteceu o diálogo entre as áreas do conhecimento e quais delas colaboraram para que fosse possível encontrar resoluções satisfatórias para as questões levantadas pelos alunos. Além disso, vale ressaltar que, em se tratando de interdisciplinaridade, é possível que algumas disciplinas tenham mais participação que outras, pois a apropriação de conhecimentos relativos a uma dada área é feita à medida que o trabalho sugere tal necessidade, sendo possível que algumas disciplinas que colaboraram nas etapas iniciais do projeto tenham uma participação menor durante seu desenvolvimento ou mesmo tenham dado lugar a outras que sejam mais relevantes em um determinado momento.

Como comentado na subseção anterior, o trabalho desenvolvido foi baseado em gêneros textuais, por isso a disciplina que teve maior participação em todos os momentos do projeto foi a Língua Portuguesa, sendo que ela apareceu tanto em registro escrito quanto oral. Ela fez-se presente na elaboração dos e-mails, na leitura e produção de crônicas e demais textos levados aos alunos, nas interações feitas no grupo do Facebook, na produção e postagem dos vídeos em rede social, nas pesquisas e socialização de resultados com os colegas e professores, entre outros.

Também houve a presença da História, que ajudou na composição do panorama inicial de como as tecnologias digitais surgiram e seus avanços ao longo dos anos, nos relatos da história da vida de Einstein, na descoberta de quem inventou o celular e como deu-se sua evolução através dos tempos. Além disso, nos temas de pesquisa surgiram questões que essa disciplina pôde ajudar a responder em conjunto com outras que serão apresentadas a seguir. Além disso, como as práticas aconteceram, majoritariamente, em ambiente virtual, notou-se a necessidade do auxílio da Língua Inglesa à medida que surgiram termos provenientes desse idioma nos endereços eletrônicos acessados pelos estudantes ou nos textos trabalhados em aula.

Ainda, a Física e a Química - que no Ensino Fundamental ainda estão encerradas na disciplina de Ciências - colaboraram com os temas de pesquisa para explicar, por exemplo, como funciona uma bateria de celular, como funcionam as ondas de internet por conexão wi-fi, entre outros. Por fim, pode-se dizer que, além dessas 
disciplinas, o tema transversal de como comportar-se adequadamente em ambientes virtuais foi recorrente em diversas práticas, sempre atrelado à Língua Portuguesa já mencionada anteriormente, uma vez que esse comportar-se compreendeu, principalmente, a comunicação em registros mais ou menos formais da língua.

\section{CONSIDERAÇÕES FINAIS}

Apesar da crescente aceitação, por parte dos professores, do uso das TDICs em sala de aula, ainda há aqueles que não se sentem confortáveis em usá-las, talvez porque sua formação tradicional não os preparou para isso. Nesse sentido, o PIBID se constitui como ótima alternativa aos cursos de licenciatura mais tradicionais, pois alia teoria e prática na formação de jovens docentes. Assim, os bolsistas do PIBID chegam na escola parceira preparados para usar as novas tecnologias e também abertos a aprender com os professores supervisores e os alunos.

Além do desafio de usar as TDICs, há também o de transformar práticas tradicionais de ensino e aprendizagem em práticas interdisciplinares. Novamente, os professores sentem-se apreensivos para trabalhar com esse conceito e, por isso, a colaboração dos bolsistas que levam para a sala de aula sua bagagem teórica acerca da interdisciplinaridade mostra-se de grande valor.

Diante do objetivo de unir o tema já proposto pela escola parceira - Navegar é preciso, mas conviver é imprescindível - com a interdisciplinaridade, a solução encontrada foi o trabalho com gêneros textuais veiculados de maneira on-line. Por meio de tarefas pautadas nas metodologias ativas e das intervenções dos bolsistas do PIBID, percebeu-se que os avanços dos alunos foram ao encontro dos objetivos do projeto apresentados na introdução deste artigo.

A presença das disciplinas de Língua Portuguesa, História, Língua Inglesa, Física e Química, bem como temas transversais, possibilitou construir, com os aprendizes, seu letramento digital, à medida que desenvolveram habilidades como a escrita de textos mais formais, o entendimento da importância de pesquisar em lugares seguros e confiáveis para dar qualidade ao trabalho e a importância de ser respeitoso em sua comunicação, tanto dentro quanto fora das redes sociais.

Para finalizar, pode-se dizer que os alunos cresceram muito em todas as disciplinas como pudemos perceber durante as aulas e através de posteriores relatos dos 
professores, que afirmaram que os aprendizes passaram a enxergar as disciplinas de maneira menos compartimentalizada, o que passou também a ser perceptível no discurso deles em sala de aula. Ainda, percebeu-se que a reescrita dos textos em conjunto com os alunos, corrigindo os pontos salientados pelo professor como passíveis de mudança constituiu-se como um locus de discussão que possibilitou aprimorar os conhecimentos linguísticos e uma parte essencial do processo de qualificação da escrita dos estudantes.

\section{REFERÊNCIAS}

AFONSO, Carlos. Internet no Brasil - alguns dos desafios a enfrentar. Informática Pública, v. 4, n. 2, p. 169-184, 2002. Disponível em: <www.ip.pbh.gov.br/ANO4_N2_PDF/ip0402afonso.pdf>. Acesso em: 12 nov. 2015.

ALVES, Raílda F.; BRASILEIRO, Maria do Carmo E.; BRITO, Suerde M. de O. Brito Interdisciplinaridade: um conceito em construção. Episteme. Porto Alegre: UFRGS, n. 19, p. 139-148, jul./dez. 2004. Disponível em:

$<$ http://www.joinville.udesc.br/portal/professores/regina/materiais/interdisciplinaridade _artigo2.pdf>. Acesso em: 12 nov. 2015.

ARAUJO, Layanna Martha Pires de; CARVALHO, Silvania Cápua. As contribuições das TDICs para o ensino de línguas estrangeiras. XI EVIDOSOL e VIII CILTEC, Minas Gerais, junho/2014. Disponível em: <http://docplayer.com.br/2795886-Ascontribuicoes-das-tdics-para-o-ensino-de-linguas-estrangeiras.html>. Acesso em: 12 nov. 2015

BRASIL. Secretaria de Educação Fundamental. Parâmetros Curriculares Nacionais: terceiro e quarto ciclos do ensino fundamental: introdução aos parâmetros curriculares nacionais. Brasília: MEC/SEF, 1998.

BRASIL. Ministério da Educação. Secretaria de Educação Média e Tecnológica. Parâmetros Curriculares Nacionais: Ensino Médio. Brasília: MEC/SEF, 2002.

CARLOS, Jairo Gonçalves. Interdisciplinaridade no Ensino Médio: desafios e potencialidades. 172f. Dissertação (Mestrado em Ensino de Física) - Universidade de Brasília, Brasília, 2001.

COSCARELLI, Carla Viana. Linkando as ideias dos textos. In: ARAÚJO, Julio Cesar; DIEB, Messias (orgs). Letramentos na web: gêneros, interação e ensino. Fortaleza: Edições UFC, 2009. p. 13-20.

DEMO, Pedro. Conhecimento moderno: sobre ética e intervenção do conhecimento. Petrópolis: Vozes, 1998. 
DUARTE, Newton. Sociedade do conhecimento ou sociedade das ilusões?: quatro ensaios crítico-dialéticos em filosofia da educação. Campinas: Autores Associados, 2003.

FORQUIN, Jean-Claude. Relações entre gerações e processos educativos: transmissões e transformações. São Paulo: 2003. Disponível em:

$<$ http://www.sescsp.org.br/sesc/images/ upload/conferencias/83.rtf $>$. Acesso em: 12 nov 2015 .

FREIRE, Paulo; PAPERT, Seymour. O futuro da escola. São Paulo: TV PUC, 1996.

GRANÉ, Mariona. Entrevista a Mariona Grané. In: GVIRTZ, Silvina; NECUZZI, Constanza (compil.). Educación y tecnologías: las voces de los expertos. Caba: Anses, p. 65-73, 2011. Disponível em: <http://www.oei.es/conectarigualdad.pdf>. Acesso em: 12 nov. 2015.

KENSKI, Vani Moreira. Educação e tecnologias: o novo ritmo da informação. 8. ed. São Paulo: Papirus, 2011.

LEIS, Héctor Ricardo. Sobre o conceito de interdisciplinaridade. Cadernos de Pesquisa Interdisciplinar em Ciências Humanas, Florianópolis, pp. 3-22, 07 jul. 2005. Disponível em: <http://ppgich.ufsc.br/files/2009/12/TextoCaderno73.pdf>. Acesso em: 25 fev. 2016.

LÉVY, Pierre. Cibercultura. São Paulo: Ed. 34, 1999.

LOMBARDIA, Pilar García. Quem é a geração Y? HSM Management, São Paulo, n.70, p.1-7.Set./out. 2008.

MORIN, Edgar. A cabeça bem feita: repensar a reforma, reformar o pensamento. 15. ed. Rio de Janeiro: Bertrand do Brasil, 2008.

OLIVEIRA, Sidnei. Geração Y: Era das Conexões, tempo de Relacionamentos. São Paulo: Clube de Autores, 2009.

PAVIANI, Jayme. Interdisciplinaridade: conceitos e distinções. 2. ed. Caxias do Sul: Educs, 2008.

PIRES, Marília Freitas de Campos. Multidisciplinaridade, Interdisciplinaridade e Transdisciplinaridade no ensino. Interface, v. 2, p. 173-182, 1998. Disponível em: <http://hdl.handle.net/11449/30363> Acesso em: 13 set. 2017

POZO, Juan Ignãcio; ECHEVERRÍA, María del Puy Pérez. As concepções dos professores sobre a aprendizagem: rumo a uma nova cultura educacional. Pátio - revista pedagógica, ano IV, n. 16, p. 19-23, fev./abr. 2001.

SILVA, Luiza Helena Oliveira da; PINTO, Francisco Neto Pereira.

Interdisciplinaridade: as práticas possíveis. Revista Querubim, ano 5, 2009. Disponível em: 
<http://www.uff.br/feuffrevistaquerubim/images/arquivos/artigos/interdisciplinaridade entre_teorias_e_prticas.pdf>. Acesso em: 12. fev. 2015.

THIESEN, Juares da Silva. A interdisciplinaridade como um movimento articulador no processo ensino-aprendizagem. Revista Brasileira de Educação, v. 13, n. 39, p 545-598. set./dez. 2008. Disponível em: <http://www.scielo.br/scielo.php?pid=S141324782008000300010\&script=sci_arttext $>$. Acesso em: 12 nov. 2015.

TOLEDO, Priscilla Bassitt Ferreira; ALBUQUERQUE, Rosa Almeida Freitas; MAGALHÃES, Ávilo Roberto de. O Comportamento da Geração Z e a Influência nas Atitudes dos Professores. In: SIMPÓSIO DE EXCELÊNCIA EM GESTÃO E TECNOLOGIA - SEGeT, IX, 2012, Resende, Rio de Janeiro. Artigos... Resende: AEDB, 2012. Disponível em:

<http://www.aedb.br/seget/arquivos/artigos12/38516548.pdf>. Acesso em: 26 jan. 2016.

ZABALA, Antoni. Função social do ensino e enfoque globalizador. In:

Enfoque globalizador e pensamento complexo: uma proposta para o currículo escolar. Porto Alegre: Artmed, p. 43-87, 2002. 